Document downloaded from:

http://hdl.handle.net/10251/64261

This paper must be cited as:

Rutkowska, M.; Díaz Morales, UM.; Palomares Gimeno, AE.; Chmielarz, L. (2015). Cu and Fe modified derivatives of 2D MWW-type zeolites (MCM-22, ITQ-2 and MCM-36) as new catalysts for DeNOx process. Applied Catalysis B: Environmental. 168:531-539. doi:10.1016/j.apcatb.2015.01.016.

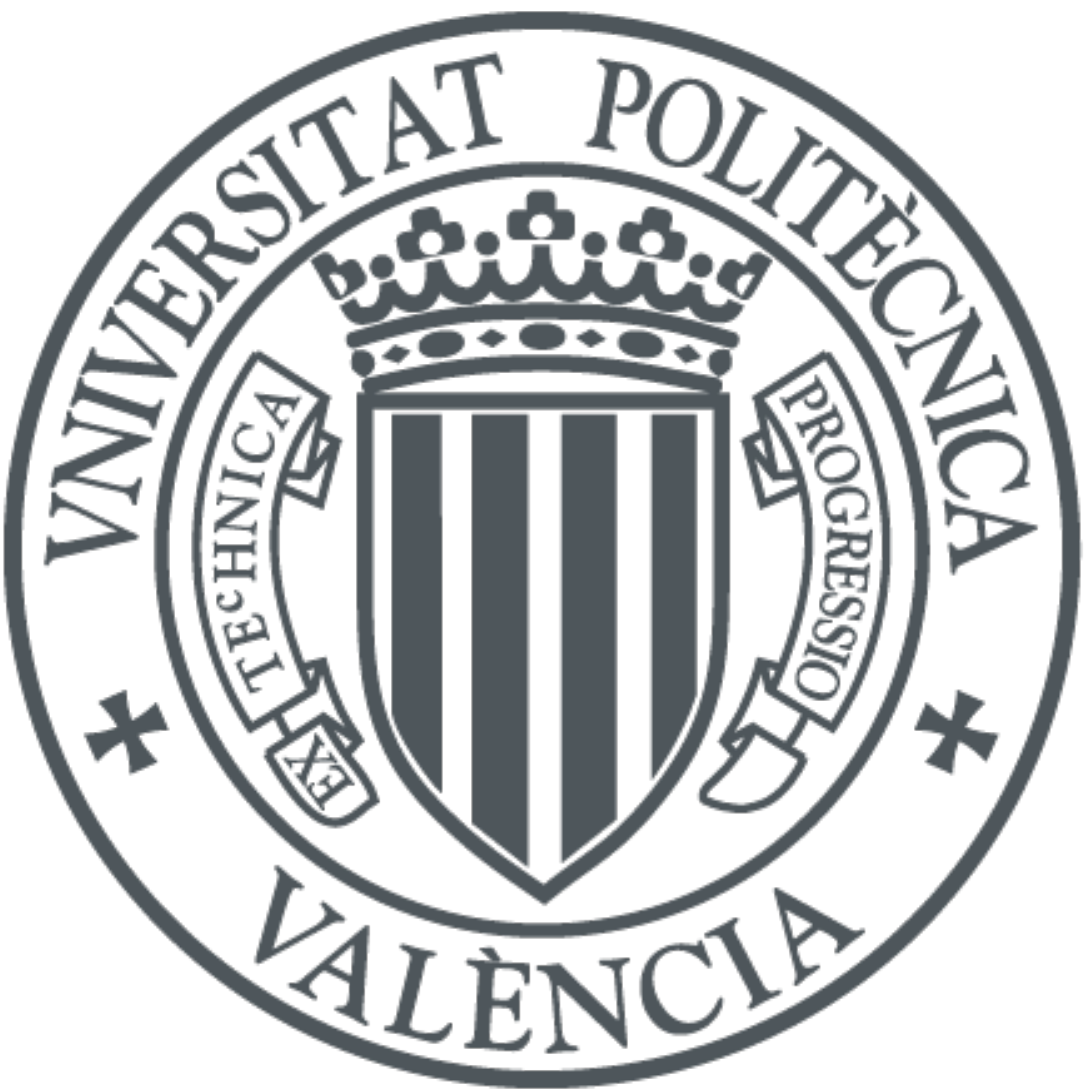

The final publication is available at

http://dx.doi.org/ 10.1016/j.apcatb.2015.01.016

Copyright Elsevier

Additional Information 


\section{Cu and Fe modified derivatives of 2D MWW-type zeolites (MCM-22, ITQ-2 and MCM-36) as new catalysts for DeNO $\mathrm{D}_{\mathrm{x}}$ process}

M. Rutkowska ${ }^{1 *}$, U. Diaz $^{2}$, A. E. Palomares ${ }^{2}$, L. Chmielarz ${ }^{1}$

${ }^{1}$ Jagiellonian University, Ingardena 3, 30-060 Kraków, Poland

${ }^{2}$ Instituto de Tecnología Química, UPV-CSIC, Universidad Politécnica de Valencia, Avenida de los Naranjos, s/n, 46022 Valencia, Spain

*Corresponding author. Tel.: +48 126632096, fax: +48 126340515. E-mail address: rutkowsm@chemia.uj.edu.pl (M. Rutkowska)

Keywords: 2D zeolites, MCM-22, ITQ-2, MCM-36, NO reduction with ammonia, $\mathrm{N}_{2} \mathrm{O}$ decomposition

Abstract

Zeolites with MWW topology (MCM-22, ITQ-2 and MCM-36) exchanged with copper and iron were studied as catalysts for selective catalytic reduction of NO with ammonia. It was shown that delamination and pillaring of layered MCM-22 zeolite resulted in the formation of ITQ-2 and MCM-36, respectively. Both these materials were characterized by MWW topology and significant contribution of mesopores.

In a series of the zeolite based catalyst the most promising results in a process of selective catalytic reduction of NO with ammonia were obtained for the copper doped samples $(\mathrm{Cu}-$ MCM-22 and Cu-ITQ-2), however catalytic performance of the studied catalytic systems strongly depends on type, content and form of deposited transition metal species. Moreover, both these catalysts were found to be catalytically stable in the DeNOx process after hydrothermal treatment. 


\section{Introduction}

Zeolites are one of the most studied group of porous materials. The great interest in zeolites is caused by their wide applications in industry as catalysts, molecular sieves and ionexchangers [1]. Despite many studies on zeolites, it is still a very interesting and developing group of materials. The future challenges in this field are associated with development of synthesis methods and modification techniques of hierarchical porous systems, layered zeolites, extra-large pore structures and chiral zeolites [2].

The conventional methods of zeolite synthesis result in microcrystalline 4-connected aluminosilicate frameworks. The post-synthesis modification (without degradation) of threedimensional structure is limited to calcination or ion-exchange, which only slightly change the lattice parameters [3]. New opportunities of zeolite frameworks modification appeared together with discovery of layered two-dimensional MCM-22 zeolite [4]. The precursor of MCM-22 consists of vertically aligned, not covalently connected layers. A single layer, showing the MWW-type structure has thickness of one unit cell and a system of two independent pore channels (10 and $12 \mathrm{MR}$ ) [5, 6]. Upon calcination of MCM-22 precursor the interlayer surfactant is removed with simultaneous 3D framework formation (through the condensation between surface silanol groups), giving a rise to MCM-22 zeolite [1].

The new opportunity in zeolite designing, connected with modification of interlayer distance, initiated an expansion of zeolite family. Beside MWW type of framework other 10 topologies were obtained in a layered form. Roth at al. [7] proposed a tabular classification of various layered forms of zeolites described in literature. In case of MWW framework the following structures were recognized: MCM-49 (3D zeolite), MCM-22(P) (ordered multi-layered precursor), EMM-10(P) (disordered multi-layered precursor), MCM-56 (mono-layer, delaminated structure), MWW-IEZ (stabilized ordered precursor), EMM-12 (stabilized 
disordered precursor), ITQ-2 (delaminated swollen precursor), MCM-36 (pillared zeolite) and MWW-BETB (organic pillared material). Among the mentioned materials, delaminated and pillared zeolites show very interesting properties resulting from the enhanced accessibility of external surface $[8,9]$.

The preparation of ITQ-2 and MCM-36 is based on the post-synthesis modification of the expanded layered zeolite precursor (MCM-22(P)). By swelling and exfoliating of MCM-22 precursor, the ITQ-2 material with disordered thin sheets (about $2.5 \mathrm{~nm}$ of thickness) and preserved 10-membered-ring (10 MR) channel system can be obtained [6]. While swelling and pillaring of MCM-22(P) with polymeric silica results in MCM-36 material with stable interlayer separation and mesopores created between pillars and zeolitic layers [10]. The advantages of ITQ-2 and MCM-36 (in comparison to 3D MWW structure), connected with greater accessibility of active sites and shorter diffusion paths, are highly desirable in catalysis, especially in case of larger molecules or non-selective reactions [11].

Layered zeolites are relatively young group of materials and there is still a large need of intensive research concerning their future application in catalytic processes. First reports providing satisfying information about their promising activity in different reactions were reported in scientific literature. E.g. Corma et al. [12] found $\mathrm{Cu}$ and $\mathrm{Co}-\mathrm{exchanged} \mathrm{MCM-22}$ as active and selective catalysts for selective catalytic reduction (SCR) of NO with propane. Another example is high efficiency of Ti modified ITQ-2 in selective epoxidation of olefins with organic hydroperoxides [13]. On the other side, MCM-36 pillared with $\mathrm{MgO}, \mathrm{Al}_{2} \mathrm{O}_{3}$ and $\mathrm{BaO}$ was found to be active catalysts for NO reduction with $\mathrm{CO}$ [14].

Analyzing the previous research results concerning the MWW-type materials, we supposed that layered materials derived from MCM-22 could be active and selective catalysts in the selective reduction of $\mathrm{NO}_{\mathrm{x}}$ with ammonia $\left(\mathrm{DeNO}_{\mathrm{x}}\right)$ process. The emission of $\mathrm{NO}_{\mathrm{x}}$ to the atmosphere is one of the main factors contributing to acid rains, depletion of ozone layer and 
greenhouse effect. The main sources of $\mathrm{NO}_{\mathrm{x}}$ emission are road traffic, power stations and chemical industry. The most efficient way of reduction of nitrogen oxides emission is their catalytic conversion [15, 16]. Zeolites from MFI, FAU and BEA families (conventional [17] and micro-mesoporous $[18,19])$ modified with $\mathrm{Fe}, \mathrm{Cu}$ and $\mathrm{Co}$ were found to be active and selective catalysts in the $\mathrm{DeNO}_{\mathrm{x}}$ process.

The scope of our studies was to examine the physicochemical properties of the $\mathrm{Cu}$ and $\mathrm{Fe}$ modified samples derived from MCM-22(P) family (MCM-22, ITQ-2 and MCM-36) and their catalytic performance in selective catalytic reduction of $\mathrm{NO}$ with $\mathrm{NH}_{3}$.

\section{Experimental methods}

\subsection{Catalysts preparation}

Synthesis of MCM-22

The synthesis of MCM-22(P) started with preparation of the synthesis mixture using the procedure described in [20]. $0.37 \mathrm{~g} \mathrm{NaOH}$ (Scharlau) and $0.67 \mathrm{~g} \mathrm{NaAl}_{2} \mathrm{O}_{3}$ (Carlo Erba), was dissolved in $80.71 \mathrm{~g}$ of Milli-Q water. In a next step $4.96 \mathrm{~g}$ of hexamethyleneimine (Aldrich) (structure-directing agent) and $6 \mathrm{~g}$ of fumed silica (Aerosil 200) were added to the mixture. The resulting slurry with $\mathrm{Si} / \mathrm{Al}$ ratio $=15$ was stirred for $2 \mathrm{~h}$ and hydrothermally treated in PTFE-lined stainless-steel autoclave with rotation $(60 \mathrm{rpm})$ at $423 \mathrm{~K}$ for 7 days. After the aging period the autoclave was quenched and the sample denoted as MCM-22(P) was filtered, washed with distilled water and dried overnight at $333 \mathrm{~K}$. After calcination (423 K for $1.5 \mathrm{~h}$, $623 \mathrm{~K}$ for $3 \mathrm{~h}$ and $853 \mathrm{~K}$ for $3 \mathrm{~h}$ ) of MCM-22(P) the reference 3D sample, denoted as MCM22, was obtained.

Synthesis of MCM-22(S) (Swelling) 
The synthesis of both ITQ-2 and MCM-36 started with the swelling of MCM-22(P), using a mixture of hexadecyltrimethylammonium $\mathrm{Br}^{-} / \mathrm{OH}^{-}$and tetrapropylammonium $\mathrm{Br}^{-} / \mathrm{OH}^{-}$ aqueous solution (100 $\mathrm{g}$ of $\mathrm{CTMA}^{+} \mathrm{Br}^{-} / \mathrm{OH}^{-}(\sim 50 \%$ ionic exchange, $\sim 25 \mathrm{wt} . \%)$ and $30 \mathrm{~g} \mathrm{TPA}{ }^{+}$ $\mathrm{Br}^{-} / \mathrm{OH}^{-}(\sim 50 \%$ ionic exchange, $\sim 40 \mathrm{wt} \%)$ per $5 \mathrm{~g}$ of layered precursor was used). The resulting slurry was stirred under reflux at $353 \mathrm{~K}$ for $16 \mathrm{~h}$. The final product, denoted as MCM-22(S), was used for preparation of the delaminated (ITQ-2) and pillared (MCM-36) samples.

\section{Synthesis of ITQ-2( Delamination)}

Synthesis of the ITQ-2 sample was performed using the procedure described in [21]. The mixture of the swollen sample (MCM-22(S)) was sonicated in an ultrasound bath $(50 \mathrm{~W}, 50$ $\mathrm{Hz}$ ) for $1 \mathrm{~h}$. Subsequently, the mixture was acidified with concentrated $\mathrm{HCl}$ (to facilitate the solid recovery), centrifuged (12 $000 \mathrm{rpm}, 15 \mathrm{~min}$ ) and washed with distilled water (to obtain $\mathrm{pH}=7$ ). The resulting white solid was dried overnight at $333 \mathrm{~K}$ and calcined at $813 \mathrm{~K}$ for $1 \mathrm{~h}$ in nitrogen atmosphere and at $813 \mathrm{~K}$ for $6 \mathrm{~h}$ in air atmosphere.

\section{Synthesis of MCM-36 (Pillaring)}

For the preparation of MCM-36 the slurry obtained after swelling of MCM-22(P) was filtered, washed with distilled water and dried at $333 \mathrm{~K}$. The resulting white solid was mixed with the pillaring agent - tetraethylorthosilicate (TEOS, 98\%, Merck) with the proportion of 1:5 wt./wt. This slurry was stirred at $353 \mathrm{~K}$ for $24 \mathrm{~h}$ under nitrogen atmosphere (procedure described in [10]). The filtered sample was washed three times with ethanol and acetone and dried overnight at $333 \mathrm{~K}$. The resulting solid was hydrolyzed in Milli-Q water with the proportion 1:10 wt./wt. at $353 \mathrm{~K}$ for $24 \mathrm{~h}$. Then the slurry was filtered, washed with water, 
dried overnight at $333 \mathrm{~K}$ and calcined at $813 \mathrm{~K}$ for $1 \mathrm{~h}$ in nitrogen atmosphere and at $813 \mathrm{~K}$ for $6 \mathrm{~h}$ in air atmosphere.

\section{Ion-exchanges}

The obtained samples (MCM-22, ITQ-2 and MCM-36) were initially rinsed with $0.04 \mathrm{M}$ solution of $\mathrm{NaNO}_{3}$ (Sigma-Aldrich) with the wt.\% ratio solid/liquid $=1 / 150$ and dried overnight at $333 \mathrm{~K}$. The $\mathrm{Na}^{+}$forms of the samples were exchanged with the solutions of $\mathrm{Cu}$ and $\mathrm{Fe}$ salts (the concentration of the salts was adjusted to the aluminum content in the samples, taking into account that the molar ratios are: $\mathrm{Cu} / \mathrm{Al}=1 / 2$ and $\mathrm{Fe} / \mathrm{Al}=1 / 3$ ). The copper exchange was carried out by immersing the zeolite in an aqueous solution of the desired amount of $\mathrm{Cu}\left(\mathrm{CO}_{2} \mathrm{CH}_{3}\right)_{2} \cdot \mathrm{H}_{2} \mathrm{O}$ (Sigma-Aldrich), with a zeolite/liquid ratio of $10 \mathrm{~g} / \mathrm{l}$ and keeping under stirring for $24 \mathrm{~h}$ at room temperature. Just before the end of the ion exchange, the $0.1 \mathrm{M}$ solution of $\mathrm{NH}_{4} \mathrm{OH}$ was added dropwise to increase the $\mathrm{pH}$ up to 6.5 (to increase the amount of introduced $\mathrm{Cu}$ in the sample). Iron was introduced to the samples by stirring with a solution of $\mathrm{FeSO}_{4} \cdot 7 \mathrm{H}_{2} \mathrm{O}$ (Sigma-Aldrich) at $358 \mathrm{~K}$ for $6 \mathrm{~h}$. The transition metal modified samples were filtered, washed with distilled water, dried at $333 \mathrm{~K}$ and finally calcined at $823 \mathrm{~K}$ for $6 \mathrm{~h}$. The codes of the catalysts are given in Table 1 .

\subsection{Catalysts characterization}

The specific surface area $\left(\mathrm{S}_{\mathrm{BET}}\right)$ of the samples was determined by $\mathrm{N}_{2}$ sorption at $77 \mathrm{~K}$ using a 3Flex v1.00 (Micromeritics) automated gas adsorption system. Prior to the analysis, the samples were degassed under vacuum at $623 \mathrm{~K}$ for $24 \mathrm{~h}$. The specific surface area $\left(\mathrm{S}_{\mathrm{BET}}\right)$ of the samples was determined using BET (Braunauer-Emmett-Teller) model according to Rouquerol recommendations [22]. The micropore volume and specific surface area of micropores were calculated using the Harkins and Jura model ( $\mathrm{t}$-plot analysis, thickness range 
0.55-0.85 nm). The pore size distributions were determined from the adsorption branch of nitrogen isotherm by applying density functional theory (DFT). For calculations the method assuming nitrogen adsorption in cylindrical pores was used.

The X-ray diffraction (XRD) patterns of the samples were recorded using a Philips X'Pert MPD instrument. The measurements were performed in the 2 theta range of $1-40^{\circ}$ with a step of $0.03^{\circ}$.

IR measurements were performed using a Nicolet 6700 FT-IR spectrometer (Thermo Scientific) equipped with DRIFT (diffuse reflectance infrared Fourier transform) accessory and MCT detector. The dried samples were grounded with dried potassium bromide powder (4 wt.\%). The measurements were carried out in the wavenumber range of $600-4000 \mathrm{~cm}^{-1}$ with a resolution of $2 \mathrm{~cm}^{-1}$.

Pyridine adsorption-desorption experiments were carried out using Nicolet iS10 FTIR spectrometer. The calcined samples were previously activated overnight at $673 \mathrm{~K}$ under vacuum. After activation, the reference spectrum was recorded and pyridine vapor was admitted in the cell and adsorbed onto the sample. The excess of pyridine was removed in vacuum by heating for $1 \mathrm{~h}$ at 423, 523 and $623 \mathrm{~K}$, respectively. After each heating period, the sample was cooled to room temperature and IR spectrum was recorded. All the spectra were scaled according to the sample weight. Absorption coefficients calculated by Emeis [23] were used.

Coordination and aggregation of transition metal species introduced into the obtained samples were studied by UV-vis-DR spectroscopy. The measurements were performed using an Evolution 600 (Thermo) spectrophotometer in the range of 200-900 nm with a resolution of 2 nm.

The transition metals content was analyzed by means of atomic absorption spectroscopy (Spectra AA 10 Plus, Varian). 
Transmission electron microscopy (TEM) micrographs were obtained with a JEOL JEM2100F electron microscope operating at $200 \mathrm{keV}$. The samples were prepared directly by dispersing the powders onto carbon copper grids.

\subsection{Catalytic tests}

Catalytic studies of selective reduction of NO with ammonia were performed in a fixed-bed quartz microreactor. The experiments were done at atmospheric pressure and in the temperature range from 348 to $823 \mathrm{~K}$. The reactant concentrations were continuously measured using a quadrupole mass spectrometer (VG Quartz) connected directly to the reactor outlet. For each experiment $0.1 \mathrm{~g}$ of catalyst (particles sizes in the range of 0.160 $0.315 \mathrm{~mm}$ ) was placed on quartz wool plug in the reactor and outgassed in a flow of pure helium at $823 \mathrm{~K}$ for $1 \mathrm{~h}$. Then the gas mixture containing $2500 \mathrm{ppm}$ of $\mathrm{NO}, 2500 \mathrm{ppm}$ of $\mathrm{NH}_{3}$ and $25000 \mathrm{ppm}$ of $\mathrm{O}_{2}$ diluted in pure helium (total flow rate of $40 \mathrm{ml} / \mathrm{min}$ ) was used. The space time $(\tau)$ of NO in these conditions, defined as $\tau=W / \dot{n}_{N O}$ (where: $W$ is a catalyst mass, and $\dot{n}_{N O}$ is a molar flow of NO in the inlet mixture) was equal to $373 \mathrm{~g} \cdot \mathrm{h} \cdot \mathrm{mol}^{-1}$.

\section{Results and discussion}

Textural parameters of the MCM-22, ITQ-2 and MCM-36 samples, determined by nitrogen sorption measurements, are presented in Table 1. The textural properties of ITQ-2 and MCM-36 are significantly different in comparison to MCM-22. All the samples are characterized by relatively high BET surface areas. The relatively high surface area of MCM22 in comparison to the literature data (usually about $400-450 \mathrm{~m}^{2} / \mathrm{g}$ [24]) could be related to smaller crystal sizes of this material. It is worth to notice that after delamination of MCM-22 the surface area significantly increased $\left(\mathrm{S}_{\mathrm{BET}}\right.$ ITQ-2 $\left.=845 \mathrm{~m}^{2} / \mathrm{g}\right)$. External surface area and volume of macro and mesopores are considerably greater in case of ITQ-2 and MCM-36 
(especially in case of delaminated sample). In case of the MCM-36 sample the generation of mesoporosity occurred in favor of volume and surface area of micropores, which after pillarization of MCM-22(P) decreased (probably as a result of micropore blocking by interlayer silica pillars and aggregates of amorphous silica, which was possibly deposited on the outer surface of the zeolite crystals).

Introduction of copper (into MCM-22, ITQ-2 and MCM-36) and iron (into MCM-22 and ITQ-2) by ion-exchange method resulted in a decrease in BET surface areas (especially in case of the copper modified samples). Such results can be connected with a partial blocking of pores by metal oxide aggregates.

The nitrogen adsorption-desorption isotherms recorded for the MCM-22, ITQ-2 and MCM-36 samples are shown in Fig. 1. The isotherm of type I (according to the IUPAC classification), characteristic of microporous structure, was obtained for the MCM-22 sample. While in case of ITQ-2 and MCM-36 the adsorption-desorption isotherms form hysteresis loop of type H4, characteristic for micro-mesoporous materials with narrow slit-shaped like pores [25]. An increase in nitrogen adsorbed volume, observed in the range of low partial pressures, is smaller for the MCM-36 sample, what can be connected with partial blocking of micropores by the silica pillars. The shape of the isotherms reminded unchanged after deposition of transition metals (results not shown).

The XRD patterns of the series of the MWW family are presented in Fig. 2. Using the X-ray diffraction technique the characteristic fingerprint of MCM-22 as well as the inter-layer distance can be determined. The as-synthesized MCM-22 sample consists of the vertically aligned layers, thus the (001) reflections give the information about the layers separation distance. On the other side the (hk0) reflections correspond to the structure of the zeolite layer $[3,5,8]$. 
The inter-layer reflection (002) present in diffractogram of the as-synthesized sample (MCM22(P)) at approximately $6.5^{\circ} 2 \theta$ corresponds to $d$-spacing of $1.3 \mathrm{~nm}$, indicating that the separation between two MWW consecutive layers is around $2.6 \mathrm{~nm}$, both being perpendicularly ordered to $c$ axis. After calcination the inter-layer reflection (002) overlapped with an intra-layer reflection (100), providing the connection of MCM-22(P) layers into 3D zeolite (structure contraction) due to the effective condensation occurring between opposite external silanol groups, facilitated by the removal of the structural directing agents. On the other side the swelling of $\mathrm{MCM}-22(\mathrm{P})$ resulted in an intense of low angle reflection corresponding to $d$-spacing of $4.5 \mathrm{~nm}$, accompanied by disappearance of (002) and coalescing of (101) and (102) reflections. These facts, together with an appearance of a broad reflection at about $5^{\circ} 2 \theta$ (which probably arises from the originally discreet (101) and (102) reflections [5]) prove the successful swelling of the parent MCM-22 sample.

In the case of diffractograms recorded for the delaminated (ITQ-2) and pillared (MCM-36) samples, the 002 reflection is absent what is related with the disordered layer structure (delaminated structure). It is worth to notice that in all the samples the (100) reflection remained unchanged, proving that the internal structure of the individual zeolitic layers was not changed by the delamination and pillarization post-synthesis treatments. The same phenomenon occurs with the other reflections corresponding to (hk0) Miller's indexes, assigned to plane $a b$ of the sheets. Moreover, the explicit separation between the inter-layer reflections (101) and (102) was maintained after delamination and pillarization, what proves the presence of 3D ordered MCM-22 structure domains [5]. However, $2 \theta$ positions of (001) diffraction bands were substantially altered, confirming the spatial modification of the MWW layers, after pillarization or delamination processes, due to the loss of perpendicular order respect to $c$ axis. 
The acidity of the samples, related to the presence of $\mathrm{Al}$ in the zeolite framework was studied by pyridine sorption measurements. The FT-IR spectra of the samples before and after pyridine chemisorption (at 423, 523 and $623 \mathrm{~K}$ ) in the $v(\mathrm{OH})$ and pyridine ring vibrations regions are shown in Fig. 3. During adsorption of pyridine, the band at about $3630 \mathrm{~cm}^{-1}$ (resulting from $\mathrm{OH}$ groups bridged between framework $\mathrm{Si}$ and $\mathrm{Al}$ atoms [26]) disappeared and simultaneously new bands in the range of $1400-1700 \mathrm{~cm}^{-1}$ appeared. The band at about $1545 \mathrm{~cm}^{-1}$ results from ring vibrations of $\mathrm{PyH}^{+}$ions (Brönsted acid sites), while the band at about $1455 \mathrm{~cm}^{-1}$ comes from vibrations of Py-bounded coordinately to Lewis acid cites. Moreover, during pyridine sorption, the intensity of the band at about $3745 \mathrm{~cm}^{-1}$ was slightly reduced, what proves that the external silanols also participate (in small extent) in the generation of $\mathrm{PyH}^{+}$ions [27]. Degassing of the sample at increasing temperatures resulted in a decrease of the peaks associated with adsorbed pyridine, especially in the form of $\mathrm{PyH}^{+}$ions. Only small changes in the case of Lewis-bounded Py indicated the presence of very strong acid framework Al sites.

The concentrations of Lewis and Brönsted acid sites for the MCM-22, ITQ-2 and MCM-36 samples are collected in Table 2. For each sample the total amount of Brönsted acid sites, related to the presence of tetrahedral coordinated aluminum, is higher than the total amount of Lewis acid cites. Delamination of MCM-22 resulted in a significant decrease in the concentration of Brönsted acid sites, what can be associated with a partial dealumination of zeolite that occurred during the exfoliation process (in case of MCM-36 this effect was very weak). However, both delamination and pillarization processes decreased the strength of Brönsted acid sites. Our findings are in agreement with the results reported by Góra-Marek et al. [28] who studied the acidic properties of MCM-22 and ITQ-2 by IR spectroscopy (CO, $\mathrm{N}_{2}$, $\mathrm{NH}_{3}$, and 1,3,5-trimethylbenzene sorption). 
For the samples modified with $\mathrm{Cu}$ and $\mathrm{Fe}$, the concentration of Brönsted acid sites significantly decreased in favor of a great increase in Lewis type acidity (concentrations of Lewis and Brönsted acid sites for the ion-exchanged samples are not shown). A decrease in the intensity of the band related to vibrations in pyridinium cations confirms the effective exchange of protons by transition metals cations (proves the presence of mononuclear $\mathrm{Cu}$ and Fe cations in the samples) [29].

The changes in surface concentration of chemisorbed pyridine induced by the temperature treatment of the pre-adsorbed samples are presented in Fig. 4. The strongest acid sites are present in the pure supports - MCM-22, ITQ-2 and MCM-36. After ion-exchange with $\mathrm{Cu}$, the total concentration of acid sites (in MCM-22 and ITQ-2) increased. An opposite effect was observed for deposition of iron. This phenomenon can be connected with a high content of copper in the samples, by which the Lewis sites were generated not only in favor of Brönsted acid sites (ion-exchange positions), but also by $\mathrm{Cu}$ species (possibly also in the form of oligomeric species) deposited on the samples surface. On the other side, iron was introduced in significantly lower amount. Probably, not all ion exchange position were occupied by $\mathrm{Fe}^{3+}$ cations. Moreover, one Lewis site related to $\mathrm{Fe}^{3+}$ ion was generated in favor of three Brönsted sites.

Fig. 5 shows the UV-vis-DR spectra of MCM-22, ITQ-2 and MCM-36 modified with $\mathrm{Cu}$ (Fig. 5 a) as well as MCM-22 and ITQ-2 modified with Fe (Fig. 5 b). The UV-vis-DR spectra recorded for the $\mathrm{Cu}$-modified samples show a strong absorption below $400 \mathrm{~nm}$. The region between $200-250 \mathrm{~nm}$ is characteristic to the presence of monomeric $\mathrm{Cu}^{2+}$ ions interacting with oxygen in the zeolite crystal lattice $\left(\mathrm{LMCT}, \mathrm{O}^{2-} \rightarrow \mathrm{Cu}^{2+}\right.$ ). While, the range between $250-400$ $\mathrm{nm}$ (visible in the spectra of $\mathrm{Cu}-\mathrm{MCM}-22$ and $\mathrm{Cu}-\mathrm{MCM}-36)$ is typical for the presence of copper in the form of oligomeric $\left[\mathrm{Cu}^{2+}-\mathrm{O}^{2-}-\mathrm{Cu}^{2+}\right]$ species. The broad band at about $600-800$ $\mathrm{nm}$ can be attributed to the $\mathrm{d}-\mathrm{d}$ transition (responsible for the green color of the sample) in 
$\mathrm{Cu}^{2+}$ located in a distorted octahedral coordination [29-31]. Copper was introduced into MCM-22 and MCM-36 in various forms, however in the ITQ-2 sample copper is present mainly in the form of monomeric $\mathrm{Cu}^{2+}$ cations, what can be connected with a better accessibility of the ion-exchange positions in delaminated material. The broad band present around $800 \mathrm{~nm}$ proves deposition of bulky $\mathrm{CuO}$ aggregates on the samples surface (result of $\mathrm{NH}_{4} \mathrm{OH}$ addition just before the end of the ion-exchange process). The intensity of the band corresponds with the total amount of introduced $\mathrm{Cu}$ into the samples, determined using ICP technique (Tab. 1).

The samples modified with iron (Fig. 5b) exhibit absorption bands in the range of 200-650 $\mathrm{nm}$. The absorption region corresponding to monomeric $\mathrm{Fe}^{3+}$ ions in tetrahedral coordination is located below $250 \mathrm{~nm}$, for monomeric $\mathrm{Fe}^{3+}$ ions in octahedral coordination in the range of 250-300 nm, for small oligomeric $\mathrm{Fe}_{\mathrm{x}} \mathrm{O}_{\mathrm{y}}$ species in the range of 300-400 nm, while for $\mathrm{Fe}_{2} \mathrm{O}_{3}$ nanoparticles above $400 \mathrm{~nm}$ [32]. Iron was introduced to the MCM-22 sample in four possible forms (mononuclear cations in tetrahedral and octahedral coordination, oligomeric iron oxide clusters and $\mathrm{Fe}_{2} \mathrm{O}_{3}$ nanoparticles). However, the position of the absorption maximum shows that mononuclear $\mathrm{Fe}^{3+}$ ions in octahedral coordination are a dominant form of iron introduced into this zeolitic sample. Similar results were obtained for Fe-ITQ-2. However, in the spectra of this sample the band characteristic for $\mathrm{Fe}_{2} \mathrm{O}_{3}$ nanoparticles is absent. Thus, it seems that the delamination of the zeolite structure makes the ion-exchange positions more available and prevents clustering of iron.

The obtained zeolitic materials, modified with $\mathrm{Cu}$ and $\mathrm{Fe}$, were tested as catalysts in selective catalytic reduction of NO with ammonia (Fig. 6). Due to differences in transition metal content the catalytic activity of the samples from $\mathrm{Cu}$ and $\mathrm{Fe}$ series were considered separately. The $\mathrm{Cu}$ doped samples exhibit a very high activity in a broad temperature range. For these catalysts, the NO conversion starts at about $398 \mathrm{~K}$ and reaches $100 \%$ at about $573 \mathrm{~K}$. A 
decrease in NO conversion at higher temperatures $[33,34]$ is associated with a side process of direct ammonia oxidation by oxygen present in the reaction mixture. It is also worth to mention that the MWW family samples show high selectivity to $\mathrm{N}_{2}$ (above 90\%). High activity of the $\mathrm{Cu}$-doped catalysts is possibly related to high dispersion of copper species. In all the studied samples, copper is present nearly exclusively in the form of mononuclear ions and oligomeric species, which are known to be active in the DeNO ${ }_{x}$ process $[12,35,36]$. The samples presented various surface acidity as well as porous characteristics, but it seems that these properties of the catalysts only slightly influenced their catalytic performance. Thus, it is suggested that the form of copper species deposited in the zeolitic samples is a crucial parameter determining their catalytic properties in the $\mathrm{DeNO}_{\mathrm{x}}$ process. In the case of the iron doped catalysts, significant differences in catalytic activity, especially in the low temperature range (below $650 \mathrm{~K}$ ), were found. The Fe-MCM-22 sample, containing part of deposited iron in the aggregated form, was more active than Fe-ITQ-2, containing nearly exclusively iron in the form monocular iron ions. Therefore, these differences in the low-temperature activity can be explained by higher activity of more aggregated iron oxide species comparing to mononuclear $\mathrm{Fe}^{3+}$ ions in the low-temperature $\mathrm{DeNO}_{\mathrm{x}}$ process [37]. However, in this case also a significant influence of surface acidity and porous structure of the catalysts on their catalytic performance cannot be excluded.

The most promising samples (Cu-MCM-22 and $\mathrm{Cu}-\mathrm{ITQ}-2)$ were treated in water vapor atmosphere at $823 \mathrm{~K}$ for $3 \mathrm{~h}$. These exigent conditions can give very reliable information about the samples stability. The comparison of the samples activities before and after hydrothermal treatment (samples denoted as $\mathrm{Cu}-\mathrm{MCM}-22 / \mathrm{H}_{2} \mathrm{O}$ and $\mathrm{Cu}-\mathrm{ITQ}-2 / \mathrm{H}_{2} \mathrm{O}$ ) are presented in Fig. 7. In case of both the samples, the catalytic activity was not change significantly after the hydrothermal calcination conditions. Only at high temperatures the side process of ammonia oxidation was slightly more preferable for those samples. This is a very 
promising result for the possible future studies of this sample taking into account its possible commercial or industrial application. It is also worth to mention that in case of the majority of the zeolitic catalysts, such severe hydrothermal conditions significantly reduce the catalytic activity of the samples [38, 39].

The properties of the hydrothermally treated samples were studied by different techniques such as low temperature $\mathrm{N}_{2}$ sorption (Table 1), X-ray diffraction (results not shown), UV-visDR spectroscopy (results not shown) and TEM microscopy. The analyzed parameters of $\mathrm{Cu}-$ MCM-22/ $\mathrm{H}_{2} \mathrm{O}$ and Cu-ITQ-2/ $\mathrm{H}_{2} \mathrm{O}$ do not differ significantly from those obtained for the fresh samples. Thus, it could be concluded that hydrothermal treatment does not resulted in a substantial modification of the catalyst structure. Examples of such results are TEM images of the samples before and after hydrothermal treatment, presented in Fig. 8. Comparison of the recorded micrographs leads to the conclusion that the sizes of $\mathrm{CuO}$ aggregates were in the same range $(1-10 \mathrm{~nm})$ for the samples before and after hydrothermal treatment.

\section{Conclusions}

ITQ-2 and MCM-36 zeolites were obtained from layered MCM-22 zeolite precursor by its delamination and pillaring, respectively. The zeolite samples, exchanged with copper and iron, were found to be active and selective catalysts of selective catalytic reduction of NO with ammonia. The copper containing catalysts presented very good activity and selectivity in the DeNOx process in a broad temperature range. The side process of ammonia oxidation was very limited and observed only at higher temperatures.

It is worth to note that similar activity of $\mathrm{Cu}-\mathrm{MCM}-22, \mathrm{Cu}-\mathrm{ITQ}-2$ and $\mathrm{Cu}-\mathrm{MCM}-36$ in the $\mathrm{DeNO}_{\mathrm{x}}$ process was found despite the fact that the samples differ in surface parameters, acidity as well as transition metal species content and distribution. This fact stresses the high 
activity of the used MWW zeolitic structure, as well as the high activity of the introduced copper species.

The most promising catalysts, $\mathrm{Cu}-\mathrm{MCM}-22$ and $\mathrm{Cu}-\mathrm{ITQ}-2$, were tested in stability experiments under hydrothermal conditions. Prior to the catalytic tests, the catalysts were treated in water vapor atmosphere at $823 \mathrm{~K}$ for $3 \mathrm{~h}$. Such treatment did not result in any significant changes in catalytic activity of the samples in NO reduction with ammonia. Both the samples show high resistance for such severe conditions, keeping high activity $(100 \%$ of NO conversion in the range 523-723 K) and selectivity to $\mathrm{N}_{2}$ (above $90 \%$ ). The modification of MCM-22 did not result in a significant improvement of the catalysts efficiency in the $\mathrm{DeNO}_{\mathrm{x}}$ process, also taking into account their more complex synthesis procedures in comparison to MCM-22. However, it must be stressed that MWW derivatives are very interesting materials for possible application in catalysis but their further improvement is necessary to meet requirement for their commercialization.

\section{Acknowledgements}

M.R. acknowledges the financial support from the International $\mathrm{PhD}$-studies programme at the Faculty of Chemistry Jagiellonian University within the Foundation for Polish Science MPD Programme co-financed by the EU European Regional Development Fund. The research was carried out with the equipment purchased thanks to the financial support of the European Regional Development Fund in the framework of the Polish Innovation Economy Operational Program (contract no. POIG.02.01.00-12-023/08).

U.D. and A.E.P. thank for the financial support to Spanish Government by ConsoliderIngenio MULTICAT CSD2009-00050, MAT2011-29020-C02-01 and Severo Ochoa Excellence Program SEV-2012-0267. 


\section{References}

[1] G. Bellussi, A. Carati, C. Rizzo, R. Millini, Catal. Sci. Technol. 2 (2013) 833-857

[2] J. Coronas, Chem. Eng. J. 156 (2010) 236-242

[3] W. J. Roth, J. Čejka, Catal. Sci. Technol. 1 (2011) 43-53

[4] M.E. Leonowicz, J.A. Lawton, S.L. Lawton, M.K. Rubin, Science (Washington, DC) 264 (1994) 1910-1913

[5] W. J. Roth, D. L. Dorset, Micropor. Mesopor. Mat. 142 (2011) 32-36

[6] A. Corma, V. Fornés, J.M. Guil, S. Pergher, Th.L.M. Maesen, J.G. Buglass, Micropor. Mesopor. Mat. 38 (2000) 301-309

[7] W.J. Roth, B. Gil, B. Marszalek, Catal. Today, 227 (2014) 9-14

[8] U. Díaz, ISRN Chem. Eng. 2012 (2012) 1-35

[9] U. Díaz, A. Corma, Dalton Trans. 43 (2014) 10292-10316

[10] Y.J. He, G.S. Nivarthy, F. Eder, K. Seshan, J.A. Lercher, Micropor. Mesopor. Mat. 25 (1998) 207-224

[11] A. Corma, V. Fornés, S. B. Pergher, Th. L. M. Maesen, J. G. Buglass, Nature, 396 (1998) $353-356$

[12] A. Corma, A.E. Palomares, V. Fornés, Res. Chem. Intermed. 24 (1998) 613-623

[13] A. Corma, U. Díaz, V. Fornés, J. L. Jordá, M. Domine, F. Rey, Chem. Commun. (1999) $779-780$

[14] J-O. Barth, A. Jentys, E.F. Iliopoulou, I.A. Vasalos, J.A. Lercher, J. Catal. 227 (2004) $117-129$

[15] F. Kapteijn, J. Rodriguez-Mirasol, J.A. Moulijn, Micropor. Mesopor. Mat. 9 (1996) 2564

[16] P. Granger,V. I. Parvulescu, Chem. Rev. 111 (2011) 3155-3207 
[17] M. Rutkowska, L. Chmielarz, M. Jabłońska, C. J. Van Oers, P. Cool, J. Porous Mater. $21(2014) 91-98$

[18] M. Rutkowska, L. Chmielarz, D. Macina, Z. Piwowarska, B. Dudek, A. Adamski, S. Witkowski, Z. Sojka, L. Obalová, C. Van Oers, P. Cool, Appl. Catal. B: Environ. 146 (2014) $112-122$

[19] M. Rutkowska, L. Chmielarz, D. Macina, B. Dudek, C. Van Oers, P. Cool, JCAMS 1 (2013) 48-55

[20] A. Corma, C. Corell, J. Pérez-Pariente, Zeolites, 15 (1998) 2-8

[21] U. Díaz, V. Fornés, A. Corma, Micropor. Mesopor. Mat. 90 (2006) 73-80

[22] J. Rouquerol, P. Llewellyn, F. Rouquerol, Studies in Surface Science and Catalysis 160 (2007) 49

[23] C.A. Emeis, J. Catal. 141(1993)347

[24] B. Gil, W. Makowski, B. Marszalek, W.J. Roth, M. Kubu, J. Čejka, Z. Olejniczak, Dalton Trans. 43 (2014) 10501-10511

[25] S. Lowell, Joan E. Shields, Martin A. Thomas, Matthias Thommes, Particle Technology Series, $16(2004)$

[26] K. Góra-Marek, J. Datka, App. Catal. A:Gen. 302(2006)104-109

[27] R.M. Mihályi, K. Lázár, M. Kollár, F. Lónyi, G. Pál-Borbély, Á. Szegedi, Micropor. Mesopor. Mater. 110(2008)51-63

[28] K. Góra-Marek, J. Datka, Stud. Surf. Sci. Catal. 158(2005)837-844

[29] P. Kaminski, I. Sobczak, P. Decyk, M. Ziolek, W.J. Roth, B. Campo, M. Daturi, J. Phys. Chem. C 117(2013)2147-2159

[30] H. Praliaud, S. Mikhailenko, Z. Chajar, M. Primet, Appl. Catal. B: Environ. 6(1998)359374 
[31] S.K. Das, S. Mukherjee, L.M.F. Lopes, L.M. Ilharco, A.M. Ferraria, A.M. Botelho do Regob, A.J.L. Pombeiro, Dalton Trans. 43(2014)3215-3226

[32] J. Pérez-Ramiréz, J.C. Groen, A. Brückner, M.S. Kumar, U. Bentrup, M.N. Bebbagh, L.A. Villaescusa, J. Catal. 232 (2005) 318-334

[33] P. Boroń, L. Chmielarz, J. Gurgul, K. Łątka, T. Shishido, J-M. Krafft, S. Dzwigaj, Appl. Catal. B: Environ. 138-139 (2013) 434-445

[34] L. Chmielarz, M. Wojciechowska, M. Rutkowska, A. Adamski, A. Węgrzyn, A. Kowalczyk, B. Dudek, P. Boroń, M. Michalik, A. Matusiewicz, Catal. Today 191(2012)25-31

[35] B.I. Palella, R. Pirone, G. Russo, A. Albuquerque, H.O. Pastore, M. Cadoni, A. Frache, L. Marchese, Catal. Comm. 5 (2004) 191-194

[36] L. Chmielarz, P. Kuśtrowski, Z. Piwowarska, B. Dudek, B. Gil, M. Michalik, Appl. Catal. B: Environ. 88(2009)331-340

[37] L. Chmielarz, M. Wojciechowska, M. Rutkowska, A. Adamski, A. Wegrzyn, A. Kowalczyk, B. Dudek, P. Boroń, M. Michalik, A. Matusiewicz, Catal. Today 191(2012)25-31 [38] A.E. Palomares, F. Márquez, S. Valencia, A. Corma, J. Mol Catal. A 162(2000)175-189 [39] A.E. Palomares, J.G. Prato, A. Corma, Ind. Eng. Chem. Res 42(2003)1538-1542 